\title{
XIV. On the discordancies in the results of the methods for determining the length of the simple pendulum
}

Francis Baily Esq. F.R.S.

To cite this article: Francis Baily Esq. F.R.S. (1829) XIV. On the discordancies in the results of the methods for determining the length of the simple pendulum , Philosophical Magazine Series 2, 5:26, 97-104, DOI: $10.1080 / 14786442908674928$

To link to this article: http://dx.doi.org/10.1080/14786442908674928

曲 Published online: 10 Jul 2009.

Submit your article to this journal \lceil

Џ Article views: 2

View related articles 
XIV. On the Discordancies in the Results of the Methods for determining the Length of the simple Pendulum. By Francis BAILY, Lisq. F.R.S. \&c. \&c. \&c.*

$I^{\mathrm{T}}$

$T$ is well known to many persons that I have, for some time past, been engaged in making experiments on the convertible pendulum, with a view to satisfy myself of the accuracy of the generally received determination of the length of the simple pendulum, vibrating seconds, in this latitude. The result of those experiments has convinced me that we are, at present, very far from possessing in that instrument a method of deducing a standard measure. The pendulum employed was one similar to that which has been already described in the Phil. Mag. for August last, page 137; and is in fact nothing more than a plain straight bar of brass, about 62 inches long, 2 inches wide, and $\frac{3}{8}$ of an inch thick; without any moveable weights or sliding pieces: and the knife edges are so placed that the vibrations made on them are synchronous with each other. The distance between the knife edges (the determination of which is by far the most troublesome and difficult part of the process) has been determined from a mean of nearly one hundred comparisons with Sir George Shuckburgh's standard scale; which was kindly entrusted to me for that purpose, by the Council of the Royal Society, who now possess that invaluable instrument. This distance is $39 \cdot 3069$ inches: and the number of synchronous vibrations made on the knife edges, in a mean solar day, corrected for the arc, for the temperature, for the reduction to a vacuum, and for the rate of the clock, is $86208^{\circ} 70$ : consequently, the length of the simple pendulum will be

$$
\left(\frac{86208 \cdot 7}{86400}\right)^{3} \times 89.3069=39.1330 \text { inches. }
$$

But, Captain Kater makes the length of the simple pendulum (reduced to the level of the sea) equal to 39.I3929 inches. If we strike off the last two figures, for the amount of the correction for reducing it to the level of the sea, we shall have, in round numbers, 39.139 inches as the value of Captain Kater's measure, determined near the same spot as my own: and it will be unnecessary to carry our inquiries into the value of the fourth figure in the decimal, when we disagree so much in the value of the third figure.

Knowing the accuracy with which Captain Kater's experiments were conducted, and having minutely examined every step of the process detailed by him in his excellent paper on

- Communicated by the Author.

Nero Series. Vol. 5. No. 26. Feb. 1829.

O the 
the convertible pendulum, I was naturally led to conclude that I had inadvertently committed some error, which had escaped my repeated examination. But my suspicions were removed by the result of some experiments on a pendulum of another kind; and which has presented anomalies still more remarkable.

It has been shown by M. Prony, in his Leçons de Méchanique Analytique, vol. ii, page 340 , that we may determine the length of the simple pendulum, by knowing the distance between, and the number of vibrations made by, three knife edges placed parallel to each other, and in the same vertical plane: since these elements are sufficient to enable us to determine not only the distance of either knife edge from the centre of gravity of the pendulum, but also the accelerative force of gravity, and consequently the momentum of inertia. I therefore caused a pendulum to be constructed on this principle; but, with the addition of another knife edge: thus obtaining four axes of suspension, instead of three. By which means, I could at any time get four combinations of three axes, and thus obtain a mean result much nearer the truth. I likewise caused the axes to be so placed that they should be convertible in pairs: that is, the knife edges $\mathbf{A}$ and $\mathbf{C}$ are so placed that the vibrations on them are synchronous, and the axes convertible: and the same with respect to the knife edges $B$ and $D$. In a pendulum of this kind, therefore, we may determine the length of the simple pendulum, vibrating seconds, either by the knife edges $A-C$, or the knife edges $B-D$, according to Captain Kater's plan; or from any combination of three of the knife edges, according to the method of M. Prony ; which, as it has not yet appeared in any English work, I shall here briefly describe, although at present I shall not make any practical use of it.

In the construction of Prony's pendulum it is not essential that the knife edges should be placed at different ends of the bar: unless it be intended that they

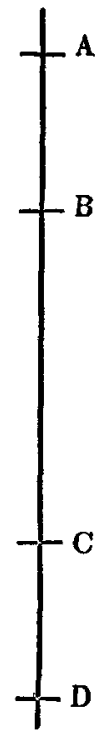
should be convertible. But it will be much more convenient that they should be so situated: and that they should also be so placed that each pair may be, as nearly as possible, equally distant from the centre of gravity. On this principle, therefore, it follows that two of the three axes, chosen for the solution of the problem, will be on one side of the centre of gravity; and the other, on the opposite side. Let the distance (in inches) between the extreme axes be denoted by $\Delta$ : and let the distance between the middle axis and that axis which is on 
the same side as it, with respect to the centre of gravity, be denoted by $\delta$. In order to avoid confusion, I shall always suppose that the pendulum, when referred to, is placed with the same end uppermost; by which means we may, in all cases, denote the three axes, above alluded to, by the designation of upper, middle, and lower axes : and each of the four combinations of three knife edges will give the length of the simple pendulum, agreeably to the formula of M.Prony, which is as follows.

By determining the number of vibrations, made in a given time, by each of the knife edges, we may obtain for the upper, middle, and lower knife edges respectively, the quantities $n^{\prime}$, $n^{\prime \prime}, n^{\prime \prime \prime}$; each of which represents a quantity $(n)$ of the form $\left(\frac{\mathrm{T}}{\pi \mathrm{N}}\right)^{8}:$ where $\mathrm{T}$ denotes the mean solar time (expressed in seconds) employed in making $\mathrm{N}$ vibrations; and $\pi$ the circumference of the circle, diameter equal to unity. If $\mathrm{T}$ represent a mean solar day ( $=86400$ seconds), N will consequently denote the number of vibrations made in a mean solar day: the value of $\mathrm{N}$ being always supposed to be corrected for the magnitude of the arc, the expansion of the pendulum, the reduction to a vacuum, and the rate of the clock. Either of the above quantities $\left(n^{\prime}, n^{\prime \prime}, n^{\prime \prime \prime}\right)$ thus deduced, being multiplied by the accelerative force of gravity $(g)$, will give the length of the pendulum synchronous with a pendulum corresponding to its respective axis: and by multiplying this length by $\left(\frac{\mathrm{N}}{86400}\right)^{2}$ we obtain the length of the simple pendulum vibrating seconds of mean solar time, at the given place.

The value of $g$ is determined by means of a quadratic equation in the following manner. Make

$$
\begin{aligned}
& v^{\prime}=n^{\prime \prime \prime}+n^{\prime} \\
& \nu^{\prime \prime}=n^{\prime \prime \prime}+n^{\prime \prime} \\
& y^{\prime \prime \prime}=n^{\prime \prime}-n^{\prime} \\
& a=2\left(\delta v^{\prime}+\Delta \nu^{\prime \prime \prime}\right) \\
& b=\delta^{2} v^{\prime}+2 \delta \Delta \nu^{\prime \prime}+\Delta^{8} v^{\prime \prime \prime} \\
& c=\delta \Delta\left(\Delta n^{\prime \prime}+\delta n^{\prime \prime \prime}\right)
\end{aligned}
$$

Then will the distance $(x)$ of the upper axis from the centre of gravity, the accelerative force of gravity $(g)$, and the momentum of inertia $(\mu)$, be found from the following equations,

$$
\begin{aligned}
x & =\frac{b}{2 a} \pm \sqrt{\left(\frac{b}{2 a}\right)^{8}-\frac{c}{a}} \\
g & =\frac{\delta(2 x-\delta)}{n^{\prime \prime} \delta-y^{\prime \prime \prime} x}=\frac{\Delta(2 x-\Delta)}{\delta x-\Delta n^{\prime \prime \prime}} \\
\mu & =x\left(g n^{\prime}-x\right)
\end{aligned}
$$


And the lengths of the three pendulums will be respectively,

$$
\begin{aligned}
& \text { upper }=g n^{\prime}=x+\frac{\mu}{x} \\
& \text { middle }=g n^{\prime \prime}=(x-\delta)+\frac{\mu}{(x-\delta)} \\
& \text { lower }=g n^{\prime \prime \prime}=(x-\Delta)+\frac{\mu}{(x-\Delta)}
\end{aligned}
$$

and either of these values, being multiplied by $\left(\frac{N}{86400}\right)^{9}$, will give the length of the simple pendulum vibrating seconds: where $\mathrm{N}$ must be taken equal to the number of vibrations corresponding to the axis chosen for the multiplicand.

It is in this manner that I propose at some future time to treat the definitive results which may be obtained by the pendulum here alluded to. The numerical operation, however, is so troublesome, the quantities determined by the experiments so mixed up with every step of the process, and the introduction of a slight error affects so materially the final result, that $I$ have considered it more satisfactory, in the presext viere of the subject, to deduce the length of the simple pendulum by the same means that I have adopted in the former pendulum : viz. by considering each pair of synchronous knife edges as convertible. That is, by considering the knife edges $A$ and $C$ as convertible, and the knife edges $B$ and $D$ as convertible: thus assuming them as two independent convertible pendulums, on the same bar.

From a mean of 8 measurements at various times, and differing very little from each other, and from a mean of 8 sets of experiments of about two hours each, on each knife edge, differing also very little from each other (corrected as in the former cases), $I$ find that the distance between $A$ and $C$ is 39.3038 inches, and the number of synchronous vibrations 86218.3: and that the distance between $B$ and $D$ is 39.3084 inches, and the number of synchronous vibrations $86204 \cdot 6$. Consequently the length of the simple pendulum will be

$$
\begin{aligned}
& \text { by } \mathrm{A} \cdot \mathrm{C}=\left(\frac{86218 \cdot 3}{86400}\right)^{2} \times 39 \cdot 3038=39 \cdot 1386 \\
& \text { by } \mathrm{B} \cdot \mathrm{D}=\left(\frac{86204 \cdot 6}{86400}\right)^{2} \times 39 \cdot 3084=39 \cdot 1307
\end{aligned}
$$

The first of these corresponds very nearly with the value deduced by Captain Kater: but whence arises the discrepancy between the two results; and the discrepancy of both of them from the former result? The form and construction of this pendulum are precisely similar to the one described in the first part of this communication; except that it is double the thickness: which, on the whole I consider a disadvantage, although 
for determining the Length of the simple Pendulum. 101

not at all bearing on the point in question. I ought not however to omit mentioning that, in order to render the respective knife edges synchronous, I caused a hole to be drilled at each end, and inserted some pieces of lead. But this, as far as our present knowledge of the pendulum extends, will have no other effect than to increase the specific gravity of the pendulum; and consequently to diminish, in a slight degree, the correction for the reduction to a vacuum; and which moreover will equally affect all the knife edges. The two ends are symmetrical.

As these are the first and only experiments (as far as my information extends) that have been made on the convertible pendulum, since those by Captain Kater, they may probably be the means of inducing others to take up and investigate the subject. I consider them, at present, only as preliminary: since it appears to me to be a waste of time to attempt any much greater degree of exactness, or to aim at any definitive results, when discordancies of such magnitude present themselves at the commencement of our inquiries, and for the existence of which we are unable to account. I am aware that $M$. Bessel has lately made a number of very interesting and valuable experiments on pendulums of various kinds, and under a variety of different circumstances: and that, from the result of those experiments, there is reason to believe that the comman correction for the reduction to a vacuum is not the same for the two positions of the convertible pendulum. But I am not aware that he has been able to deduce any formula whereby we may determine the true correction which ought in every case to be applied. The public, however, wait with much impatience for the publication of his important discoveries. Probably the only accurate mode of determining the amount of this correction, is by actual experiment:-by swinging every convertible pendulum in both positions of the knife edges; first in the open air, and afterwards in vacuo: and $I$ believe that a convertible pendulum is about to be treated in this manner, by means of a new apparatus now erecting at the Royal Observatory at Greenwich.

Whether the result of those experiments may tend to remove the discordancies here alluded to, I cannot pretend to say. If they should fail, it will be evident that the pendulum will not afford us the means of obtaining a correct and permanent standard, and which, if ever lost or destroyed, may be reproduced upon certain and unerring principles : but that we must seek for some other mode of deducing so invaluable a measure.

In the fourth volume of the Base duSystême Métrique, page $587, \mathrm{M}$. Biot has given the mean result of the experiments of

MM. Borda, 
M.M.Borda, Bouvard, Mathieu, and himself, on the length of the pendulum at Paris: which, by adding the known difference in the number of vibrations between Paris and Greenwich, will make the length of the simple pendulum, at this latter place, equal to $39 \cdot 1379$ inches. So that we have here also another discordance, amounting to more than $\cdot 001$ of an inch. I am aware that there is supposed to be a slight constant difference between the observations at Greenwich and London: but I believe that some recent experiments do not exactly accord with the theory on this point. This will, however, very shortly be more fully determined.

Were I to construct another convertible pendulum I would make the distance between the two knife edges exactly 36 inches; or as nearly so as the artist could effect it. I presume that Captain Kater selected the distance somewhere between 39.4 and 39.5 inches, in order that the proposed coincidences might be accommodated to the pendulum of the clock : at least, this circumstance weighed materially with myself, when I ordered the knife edges to be placed as nearly as possible 39.3 inches asunder. This, however, I find by experience to be a minor consideration; and inconveniences of a greater kind present themselves by adopting this plan. It is much better to select the best and most convenient length for the distance between the knife edges; and to make the pendulum of the clock subservient to the intervals required. Now, the best and most convenient length must be the very measure we are in search of; namely, the standard yard: for, when any other distance is fixed on, we may be in doubt with what part of the standard scale such distance ought to be compared. Captain Kater took the mean of 20 several lengths of 39.4 inches each; " commencing from zero of the scale, and advancing by single tenths through the space of two inches." But, if he had made a comparison with the same distance (39.4) at the other end of the scale, he would have found a difference amounting to above 0003 of an inch, in that length. Now, the distance, with which Sir George Shuckburgh himself compared the several standard yards in his time, is marked on the scale, and extends from 10 inches to 46 inches: and this I conceive to be the proper and only unit of measure which ought to be resorted to: unless we take the mean of the whole scale, as hereafter alluded to. The fact is, that the standard scale of Sir George Shuckburgh (although otherwise in excellent preservation) is not exactly straight, but is very slightly bent and twisted: and more so at one end (the zero end) than at the other. The bar is nearly 68 inches long, 1.4 inches wide, and 0.4 inches thick; and formed of two distinct pieces of brass, 
fastened and riveted together; the upper part, on which the divisions are cut, (equal to $\frac{1}{3}$ of the thickness) being of plate brass; and the under side (equal to the other ?) being of cast brass. Whether it is owing to this circumstance, or to any slight injury it may have received either in its packing (which is noro certainly not in the best order), or from some other cause, it might be difficult to decide at the present day; but it has a very small curvature upwards at the ends, of sufficient magnitude, however, to enable a common playing card to be passed with ease 2 or 3 inches underneath the zero end, when lying on a straight and plane plank : at the other end, a piece of thin paper might be passed, about the same distance. That part of the scale, which may be called the standard yard, and which (as above stated) extends from 10 inches to 46 inches, does not appear to be affected by this distortion; and consequently seems to be the most proper portion of the scale to be considered as the unit of measure.

In Captain Kater's "Account of the comparison of various British standards of linear measure," inserted in thePhil.Trans. for 1821, he has given the result of a comparison of 36 inches on four several standards, with the same distances on Sir George Shuckburgh's scale: but he has not stated what part of Sir George Shuckburgh's scale was selected. In his account, however, of the adjustment of the standard yards (Phil. Trans. 1826, page 44), he states, that the distance there used wàs taken from zero to 36 inches: leaving it therefore to be inferred that the same distance was used on the former occasion. But, would it not have been more satisfactory to have used that very distance which Sir George Shuckburgh himself adopted in his comparisons : viz. from 10 to 46 inches? or (which would perhaps have been more correct, though far more troublesome) to have taken a mean of all the 24.0 distances of 36 inches each, that might have been measured on the scale; advancing by successive tenths from zero to 24 inches?

There is also another circumstance connected with these measurements, which ought to be borne in mind. Captain Kater states (Phil. Trans. 1821, page 78) that his microscopes were attached to a stout mahogany bar, 36 inches long, and that this bar was laid upon the scale: which he considered an important advantage, inasmuch as the microscopes, being once adjusted to distinct vision, would not require re-adjusting when placed upon another scale, But he seems to have overlooked the circumstance that the bent end of Sir George Shuckburgh's scale would not present the same reading when a heavy weight was placed upon it: neither do I think it adviseable at any time to resort to such a method. These are points which ought to be taken into consideration at any future time, if the 
104 Mr. Ivory's Observations on Mr. Meikle's Reply, \&c.

pendulum (as I presume it will be) should ever be re-measured and re-swung with a view to obtain a more correct and permanent comparison for a standard measure; for, in a national work, no labour or expense ought to be spared, in order to obtain the greatest possible accuracy.

I ought not to omit mentioning that the two convertible pendulums (the one of iron, and the other of copper) belonging to the Astronomical Society, and now in the care of Captain Foster, in his royage of experiment and discovery, are formed on precisely the same plan, as the pendulum alluded to in the first part of this communication. I had not an opportunity of measuring the distances between the knife edges, previous to his departare: but, on his return, it will be interesting to ascertain whether those pendulams indicate anomalies similar to those which have been the subject of this communication.

January 20 ; 1829.

Francts Barly.

XV. Some Obserrations on Mr. Meikle's Reply, published in the last Number of the Quarterly Journal of Science. By JAMES IVORY, Esq. M.A. F.R.S. \&c.*

MR. MEIKLE seems resolutely bent on effecting the 1 thorough reform, and on weeding out every blemish from mathematical science. For my part, I am fully resolved to oppose no obstacle to the accomplishment of so laudable a project. On the contrary he may reckon upon it as a thing not doubtful, that I shall approve and adopt every improvement he may be able to establish on good grounds.

$\mathrm{He}$ is no less bent on giving to what he calls my formula any shape, and on making any use of it, he pleases. There seems, however, to be some misgiving on this point; for, in a note, he calls upon his readers to recollect what the formula is. On the other hand, I call upon them to go back to the principles from which the formula is deduced, this being the best way to judge of its import and to guide in its right application.

In this Journal for February 1827, p. 94, I have arrived at this conclusion:

" The heat extricated from air when it undergoes a given condensation, is equal to $\frac{3}{8}$ of the diminution of temperature reguired to produce the same condensation, the pressure being constant."

And as the same quantity of heat, which is evolved by a

* Communicated by the Author. 